\title{
The Effect of Processing Parameters on HTS Tube Characteristics
}

\author{
Sengho Jung and Guneik Jang ${ }^{\mathrm{a}}$ \\ Department of Materials Engineering, Chungbuk National Unicersity, Gaesin-dong, \\ Heungdeok-gu, Cheongju-si, Chungbuk 361-763, Korea \\ Dongwoo Ha \\ Korea Electrotechnology Research Institute, Seongju-dong, Changwoni, Gyeongnam 641-120, Korea \\ Taehyun Sung \\ Korea Electric Power Research Institute, Munji-dong, Yuseong-gu, Daejeon 305-380, Korea
}

${ }^{a}$ E-mail : gejang@chungbuk.ac.kr

(Received February 3 2004, Accepted March 8 2004)

\begin{abstract}
High-temperature Superconductor(HTS) tubes were fabricated in terms of different chemical compositions and various $\mathrm{SrSO}_{4}$ additions by centrifugal forming method. For powder melting by induction the optimum range of melting temperatures and preheating temperature were $1050{ }^{\circ} \mathrm{C}, 1100{ }^{\circ} \mathrm{C}$ and $550{ }^{\circ} \mathrm{C}$ for $30 \mathrm{~min}$, respectively. The mould rotating speed was 1000 rpm. A tube was annealed at $840{ }^{\circ} \mathrm{C}$ for 72 hours in oxygen atmosphere. The plates like grains more than $20 \mu \mathrm{m}$ were well developed along the rotating direction of mould regardless of initial chemical compositions and the amounts of $\mathrm{SrSO}_{4}$ in $\mathrm{Bi} 2212$. The specimen with $\mathrm{Bi} 2212$ composition exhibited $\mathrm{T}_{\mathrm{c}}$ of $83 \mathrm{~K}$, while the specimens fabricated with other compositions are lower than $60 \mathrm{~K}$. The measured $\mathrm{I}_{\mathrm{c}}$ and $\mathrm{J}_{\mathrm{c}}$ at $77 \mathrm{~K}(\mathrm{~B}=0 \mathrm{~T})$ in $\mathrm{Bi} 2212$ with $7 \% \mathrm{SrSO}_{4}$ composition were about $680 \mathrm{~A}$ and $380 \mathrm{~A} / \mathrm{cm}^{2}$.
\end{abstract}

Keywords : Centrifugal forming process, HTS tube, I-V characteristics, $\mathrm{I}_{c}, \mathrm{~J}_{\mathrm{c}}$

\section{INTRODUCTION}

$\mathrm{Bi}_{2} \mathrm{Sr}_{2} \mathrm{CaCu}_{2} \mathrm{O}_{\mathrm{y}}(\mathrm{Bi} 2212)$ superconductor is one of the most promising and very attractive materials as a conductor for energy applications among other superconductors because of its easy c-axis alignment, which reduces a weak-link behaviour and maintains high sritical current density $\left(J_{c}\right)$ of a-b plane orientation. From a practical point of views these features are very important in bulk HTS applications, such as wires, urrent leads(CL) and fault current limiters(FCL). So far a number of processing techniques, such as the doctor blade method[1], the dip-coating method[2], the organometallic method[3] and the powder-in-tube method[4] have been proposed in order to fabricate zonductors with a high critical current density. All of these methods employ a slow solidification process from a partially molten state in order to enhance texturing of -axis grain alignment, Which results in a significant mprovement of intergrain coupling.

Among them, melt casting process(MCP) is well known as one of novel techniques to manufacture the 3 dimensional compact bodies[5]. MCP Bi2212 rods and the tubes have been successfully tested in a variety of current lead design[6]. The typical advantage of MCP is the fact that any geometry of superconductor with excellent current carrying properties can be easily fabricated. Additionally the temperature and field dependence of the critical current of the material is superior to that of the sintered HTS bulk parts. The HTS MCP bulk is characterized by the absence of weak links. The $\mathrm{J}_{\mathrm{c}}(77 \mathrm{~K}, \mathrm{~B}=0 \mathrm{~T})$ of the melt casted Bi2212 tubes fabricated by Aventis \& Technologies was $600{ }^{\circ} \mathrm{C} 4000$ $\mathrm{A} / \mathrm{cm}^{2}$, depending on the tube dimensions[7,8].

The Bi2212 phase is stable in a wide range of compositions and processing temperatures in a form in which $\mathbf{T}_{c}$ is influenced by the composition. It is well known that the highest $\mathrm{T}_{\mathrm{c}}(93 \mathrm{~K})$ can be obtained in $\mathrm{Sr}$ rich samples(Sr:Ca $=2.2: 0.8)$ in $\mathrm{Bi} 2212$ state[9]. However there are not many reports and results of $\mathrm{Bi}$ HTS on the solidification process after complete melting. 
In this study, Bi based tubes with 4 different chemical compositions were fabricated by a complete melting. Also as a separate work, the tube characteristics were systematically evaluated in terms of various $\mathrm{SrSO}_{4}$ amount in Bi2212. Our preliminary results indicate that electrical characteristics and microstructure were quite dependent on the processing parameters, especially initial compositions and the amounts of $\mathrm{SrSO}_{4}$. This paper will discuss about tube fabrication process and compare the tube characteristics including superconducting properties depending on compositions and amount of $\mathrm{SrSO}_{4}$ addition.

\section{EXPERIMENTAL}

As an initial composition, 4 different chemicals in $\mathrm{Bi}: \mathrm{Sr}: \mathrm{Ca}: \mathrm{Cu}=2.0: 2.0: 1.0: 2.0,2.1: 2.0: 1.0: 2.0,2.2: 1.8: 1.0: 2.0$ and 2.2:1.8:1.0:2.2 cation ratios were designed and prepared by a routine solid state reaction. Typical powders with different composition were charged into a platinum crucible for the complete melting, which is one of important processes in Centrifugal Forming Process(CFP). The melting was done by inductive heating at $1,050{ }^{\circ} \mathrm{C}$ and $1,100{ }^{\circ} \mathrm{C}$ within $5 \mathrm{~min}$ in platinum crucible in order to maintain initial composition from excessive $\mathrm{Bi}$ evaporation and any possible contamination. Following that, the solution of the melted powder was poured into the mould rotating at $1,000 \mathrm{rpm}$, which was preheated at $550{ }^{\circ} \mathrm{C}$ for $30 \mathrm{~min}$. The purpose of preheating is to prevent mechanical damage during transportation from melt to mould and solidification. For the electrical contact, $0.5 \mathrm{~mm}$ thickness of silver tape was inserted into the top and bottom of mould. Normally the specimen was mechanically stable when the melting temperature was over $1,035{ }^{\circ} \mathrm{C}$ and mould was preheated over $400{ }^{\circ} \mathrm{C}$ for $30 \mathrm{~min}$. The tube was annealed at $840{ }^{\circ} \mathrm{C}$ for 72 hours in oxygen atmosphere. Following that, the temperature was slowly cooled down to $740{ }^{\circ} \mathrm{C}$ at a rate of $1.5{ }^{\circ} \mathrm{C} / \mathrm{min}$ and then left to room temperature. As a separate work, tube characteristics were systematically studied with different weight $\%$ of $\mathrm{SrSO}_{4}$ from 0 to $15 \%$ in $\mathrm{Bi} 2212$. The fabrication stages are exactly the same as described above. For the tube fabrication, normally CFP process are mainly divided into 3 parts depending on its role and functions; the meting part by high inductive frequency, the centrifugal forming part for the tube shape and efficient microstructure control of Bi2212 phase and finally, the moulding part for tube detachment after heat treatment.

For the structural analysis and phase identification Xray diffraction method was employed. Microstructure observation was performed by a scanning electron microscopy(SEM) on both the surface and the inner side of the tube. The critical temperature $\left(\mathbf{T}_{c}\right)$ was measured by four-probe resistive method and the transport critical current $\left(I_{c}\right)$ and current density $\left(J_{c}\right)$ were determined from the current/voltage curve using a $1 \mu \mathrm{V} / \mathrm{cm}$ criterion respectively.

\section{RESULTS AND DISCUSSIONS}

Figure 1 shows Bi2212 based tubes with a silver electrode fabricated by Centrifugal Forming Process. Typical tube dimension was 30/27 mm in outside/inside diameter and $150 \mathrm{~mm}$ in length. The tube surface was quite smooth and looks homogeneous.

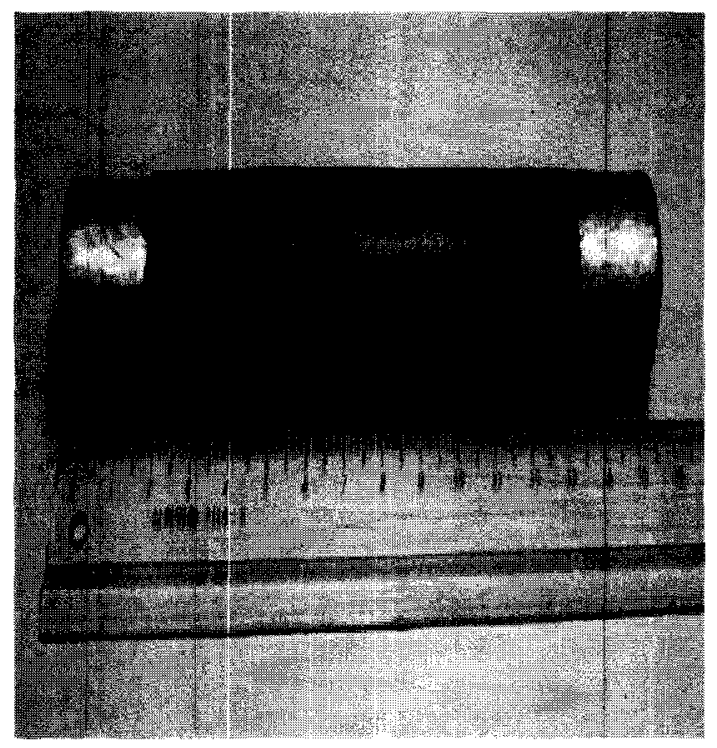

Fig. 1. Bi 2212 based tubes with a silver electrode fabricated by centrifugal forming process (dimension: 30 $\mathrm{mm} \times 150 \mathrm{~mm} \times 23 \mathrm{~mm}$ ).

For the process, the optimum range of melt and preheating temperatures and time for mould were $1050{ }^{\circ} \mathrm{C}, 1100{ }^{\circ} \mathrm{C}$ and $550{ }^{\circ} \mathrm{C}$ for $30 \mathrm{~min}$ respectively. The applied mould rotating speed was $1000 \mathrm{rpm}$. Final tube density and shape were quite dependent on many processing parameters such as melting temperature, melting time, mould rotation speed and heat treatment schedule. Especially proper adjustment in viscosity of melted powder is important to control the uniform thickness and length. It was confirmed the melted solution was solidified within $20 \mathrm{sec}$ when it contacted with a mould, which was preheated at $550{ }^{\circ} \mathrm{C}$. Therefore it seems the mould rotation speed more than $500 \mathrm{rpm}$ does not much affect texture formation. 
Figure 2 represents XRD diffraction patterns taken from the surface of tube with 4 different chemical compositions. The XRD data suggests that the phase formed after direct solidification from melt is identified is amorphous phase. After heat treatment at $840{ }^{\circ} \mathrm{C}$ for $\because 2$ hours in oxygen atmosphere diffraction patterns indicate the existence of multiphase mixture consisting of prominent $\mathrm{Bi} 2212$ with some additional peaks from ome other phases of $\mathrm{Bi} 2201, \mathrm{Cu}$-free and ( $\mathrm{Sr}, \mathrm{Ca})-\mathrm{Cu}-\mathrm{O}$ phases. It was known that $\mathrm{Bi} 2212$ phase decomposes into : liquid phase plus the solid phase of $\mathrm{Bi}-(\mathrm{Sr}, \mathrm{Ca})-\mathrm{O}(\mathrm{Cu}$ ree phase) and ( $\mathrm{Sr}, \mathrm{Ca})-\mathrm{Cu}-\mathrm{O}$ at the partial melting emperature, about $870{ }^{\circ} \mathrm{C}$ during the heating process ;10]. However Bi2212 phase was predominant regardless of compositions while the peak intensity was somewhat aried in terms of initial chemical composition.

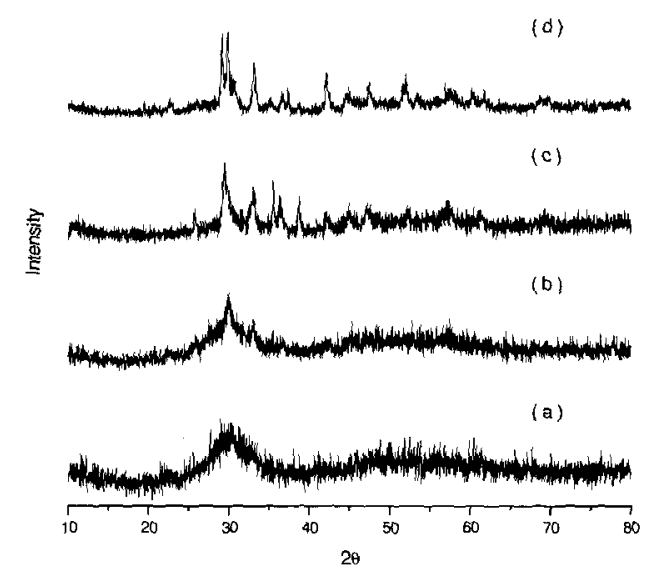

(a) before heat treatment

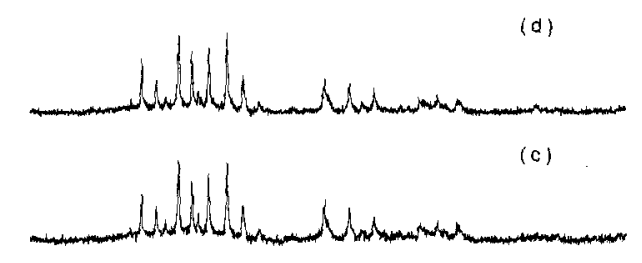

(b)

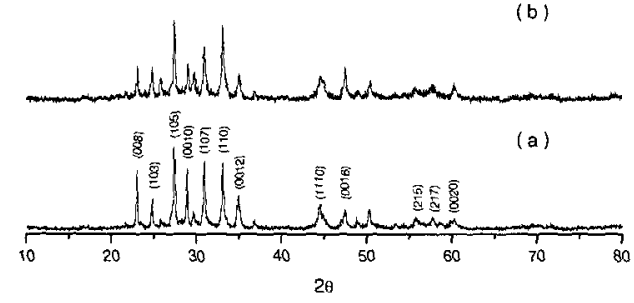

(b) after heat treatment

Fig. 2. XRD diffraction patterns taken from the surface of tube with 4 different chemical compositions:
(a) $\mathrm{Bi}_{2} \mathrm{Sr}_{2} \mathrm{Ca}_{1} \mathrm{Cu}_{2} \mathrm{O}_{\mathrm{x}}$, (b) $\mathrm{Bi}_{2.1} \mathrm{Sr}_{2} \mathrm{Ca}_{1} \mathrm{Cu}_{2} \mathrm{O}_{\mathrm{x}}$,
(c) $\mathrm{Bi}_{2.2} \mathrm{Sr}_{1.8} \mathrm{Ca}_{1} \mathrm{Cu}_{2} \mathrm{O}_{\mathrm{x}}$ and (d) $\mathrm{Bi}_{2.2} \mathrm{Sr}_{1.8} \mathrm{Ca}_{1.2} \mathrm{Cu}_{2} \mathrm{O}_{\mathrm{x}}$

Figure 3 shows diffraction patterns in terms of different $\mathrm{SrSO}_{4}$ addition in $\mathrm{Bi} 2212$ compounds after heat treatment

at $840{ }^{\circ} \mathrm{C}$ for 72 hours in oxygen atmosphere. As can be seen in Fig. 4, most of main peaks are relatively well matched with Bi2212 diffraction ones even though there are some variations of peak intensity and some minor phases as indicated above. Therefore, the XRD results suggest that the electrical properties will be hindered or influenced by the existence of some other nonsuperconducting phases.

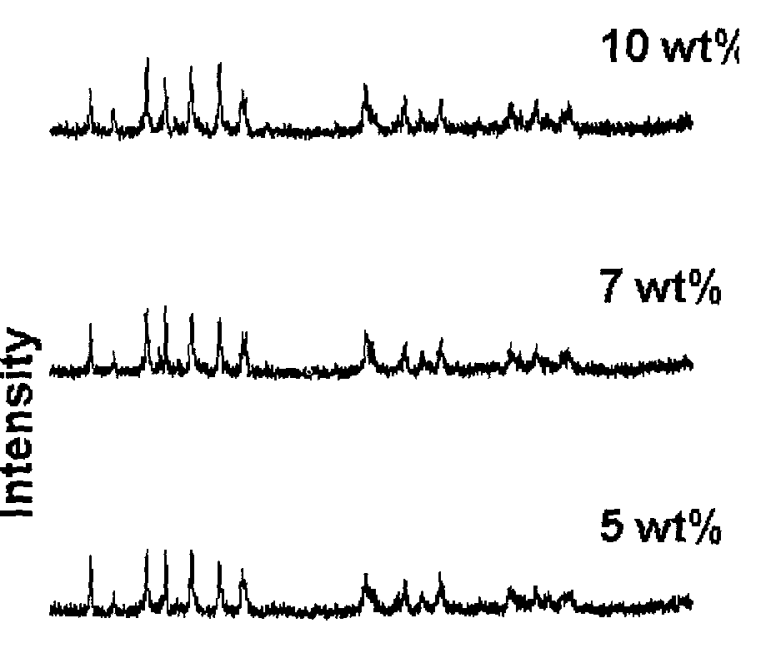

Fig. 3. XRD diffraction patterns in terms of different $\mathrm{SrSO}_{4}$ addition in Bi2212 compounds after heat treatment at $850{ }^{\circ} \mathrm{C}$ for 72 hours in oxygen atmosphere.

Figure 4 shows SEM micrographs of fractured tube surface with different compositions. The plate shaped structure more than $20 \mu \mathrm{m}$ was well developed and densified along the rotating direction of mould regardless of initial chemical compositions. Theses kinds of orientations were significant for the fractured surface close to mould as compared with one near the inner part of the tube. 


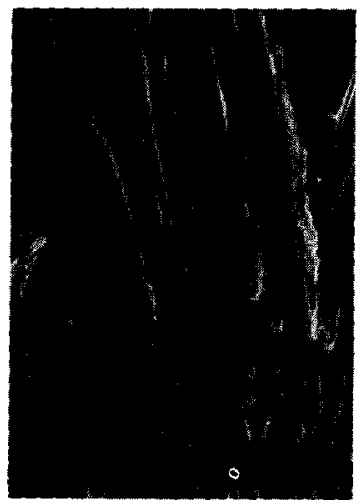

(a)

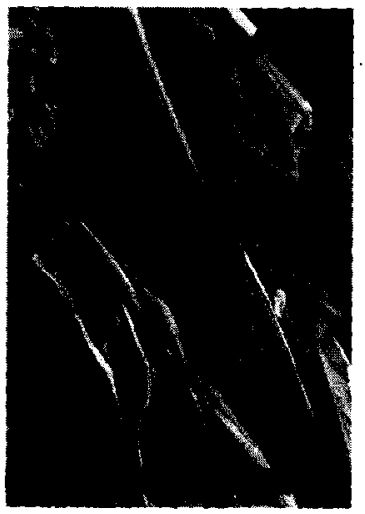

(c)

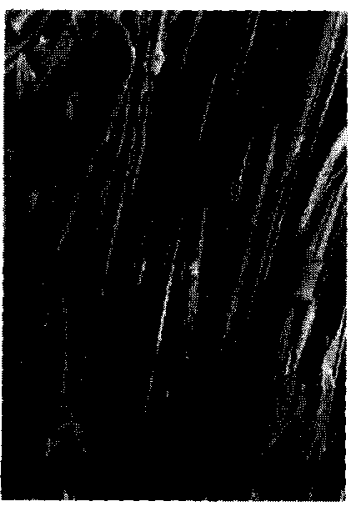

(b)

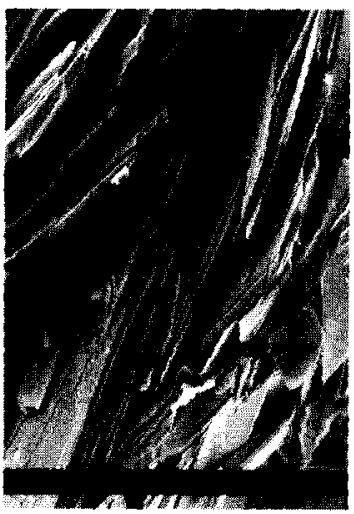

(d)
Fig. 4. SEM micrographs of fractured tube surface with different compositions:
(a) $\mathrm{Bi}_{2} \mathrm{Sr}_{2} \mathrm{Ca}_{1} \mathrm{Cu}_{2} \mathrm{O}_{\mathrm{x}}$
(b) $\mathrm{Bi}_{2.1} \mathrm{Sr}_{2} \mathrm{Ca}_{1} \mathrm{Cu}_{2} \mathrm{O}_{x}$
(c) $\mathrm{Bi}_{2.2} \mathrm{Sr}_{1.8} \mathrm{Ca}_{1} \mathrm{Cu}_{2} \mathrm{O}_{x}$ and (d) $\mathrm{Bi}_{2.2} \mathrm{Sr}_{1.8} \mathrm{Ca}_{1.2} \mathrm{Cu}_{2} \mathrm{O}_{x}$

Figure 5 represents the SEM image and EDAX results taken on the fractured surface of Bi2212 tube with 7 weight $\%$ of $\mathrm{SrSO}_{4}$. Sulfur element was strongly detected, especially near the grain boundary; even XRD data does not reveal the exact existence of Sulfur compound as a second phase

Figure 6 shows temperature-resistance of the tube fabricated with 4 different compositions. After heat treatment at $840{ }^{\circ} \mathrm{C}$ for 72 hours in oxygen atmosphere the specimen with 2212 composition exhibited $T_{c}$ of 83 $\mathrm{K}$ while the specimens with other composition are as low as $60 \mathrm{~K}$ or much lower than $60 \mathrm{~K}$ with a broad transition width and long tail, which is lower than what we expected. This can be explained by the poor grain boundary connectivity related with the phase decomposition of $\mathrm{Bi} 2212$, oxygen deficient phases, porosity and other impurities near the grain boundary area.
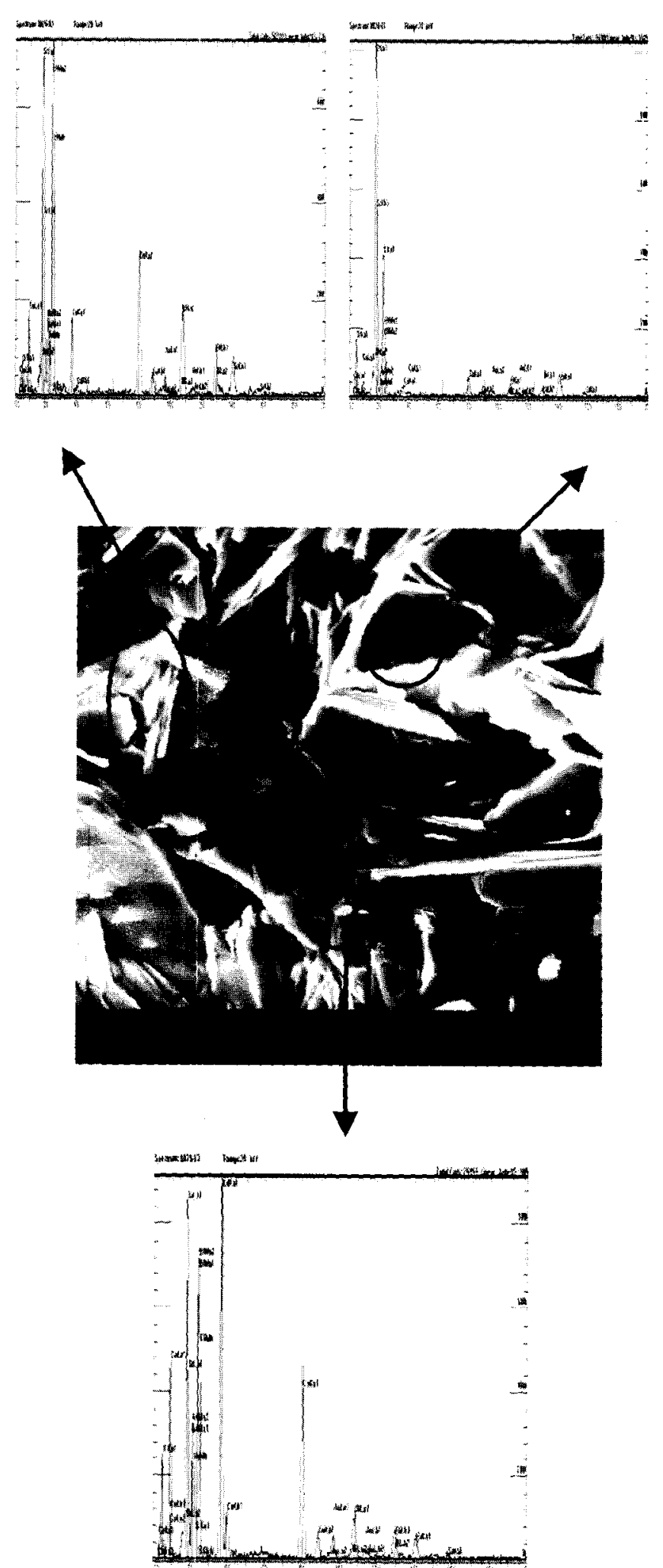

Fig. 5. SEM image and EDAX results taken on the fractured surface of $\mathrm{Bi} 2212$ tube with 7 weight $\%$ of $\mathrm{SrSO}_{4}$ 


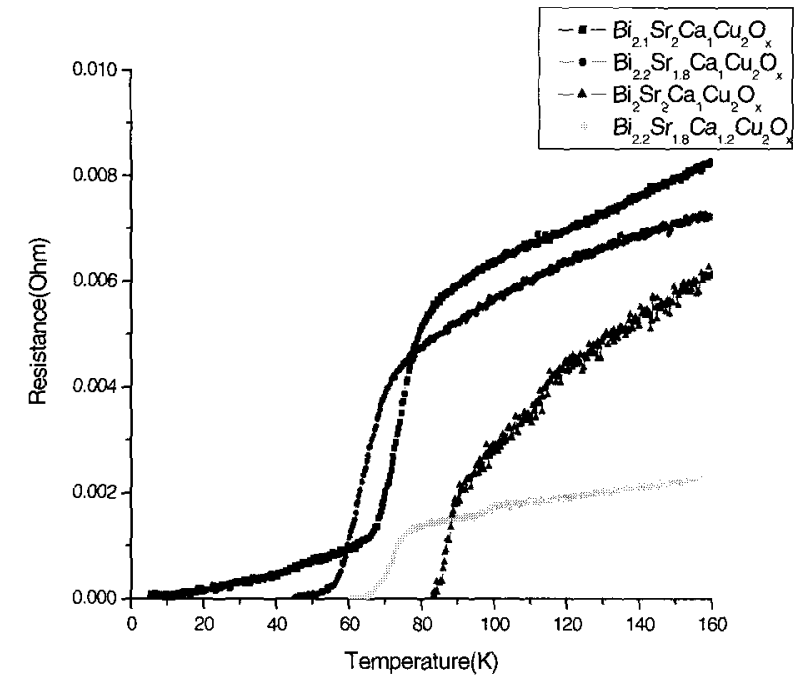

Fig. 6. Temperature-resistance characteristics of the tube abricated with 4different compositions.

Figure 7 shows the I-V characteristics of $\mathrm{Bi} 2212$ tubes, which has $30 \mathrm{~mm}$ in diameter and $60 \mathrm{~mm}$ in length, lepending on $\mathrm{SrSO}_{4}$ additions from 5 to 15 wight \%. The sritical current $\left(I_{c}\right)$ and critical current density $\left(J_{c}\right)$ ncreased as the $\mathrm{SrSO}_{4}$ weight $\%$ increased up to $7 \%$ and hen decreased beyond. It seems that increasing weight $\%$ of $\mathrm{SrSO}_{4}$, however, did not have any iignificant negative effects on $\mathrm{I}_{c}$ and $\mathrm{J}_{\mathrm{c}}$. This can be :oncluded $\mathrm{SrSO}_{4}$ addition into $\mathrm{Bi} 2212$ might be helpful or texture formation. Our preliminary results indicate hat the measured $I_{c}$ and $J_{c}$ at $77 \mathrm{~K}(B=0 \mathrm{~T})$ in $\mathrm{Bi} 2212$ with 7 weight $\%$ of $\mathrm{SrSO}_{4}$ composition were about $680 \mathrm{~A}$ and $380 \mathrm{~A} / \mathrm{cm}^{2}$ and showed the highest as compared with ther compositions.

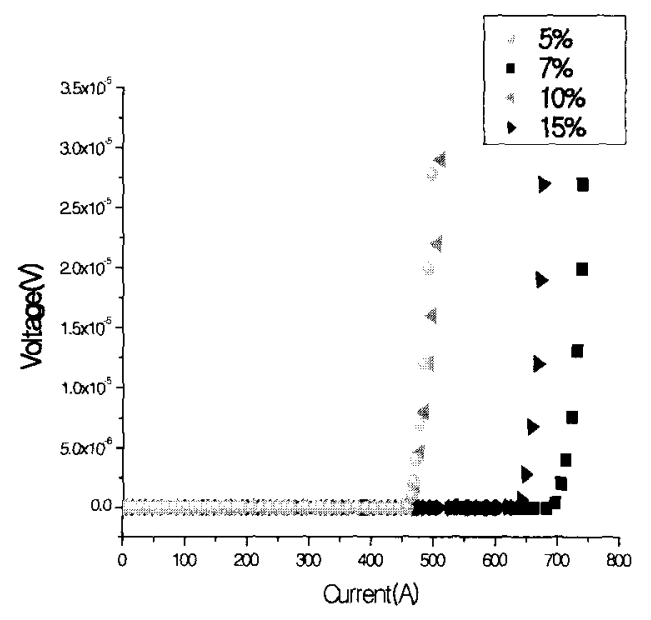

a) $I_{c}$

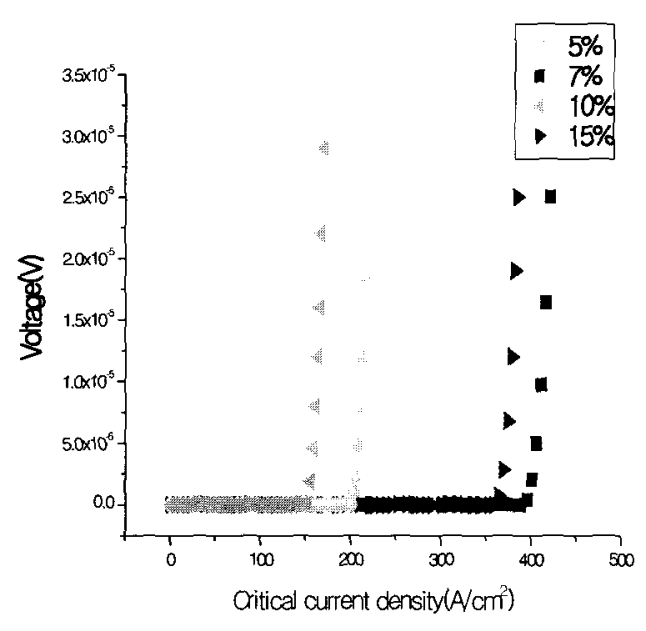

b) $\mathrm{J}_{\mathrm{c}}$

Fig. 7. I-V characteristics of Bi2212 tubes depending on $\mathrm{SrSO}_{4}$ additions from 5 to 15 weight $\%:$ a) $\mathrm{I}_{\mathrm{C}}$ and b) $\mathrm{J}_{\mathrm{C}}$.

Figure 8 show I-V measurement on tube with 7 weight $\%$ of $\mathrm{SrSO}_{4}$ at $35 \mathrm{~K}$. The measured Ic value at 35 $\mathrm{K}$ was about $1,500 \mathrm{Amp}$. Based on $\mathrm{I}-\mathrm{V}$ results, the obtained data especially in terms of $n$ value is still lower than the data taken by Hobl group even this Ic value shows somewhat promising[8]. Tc results already suggest that there are poor grain connectivity indicating phase unstability and inhomogenity. Now further detailed works to optimize the process to increase the $n$ value are still undergoing.

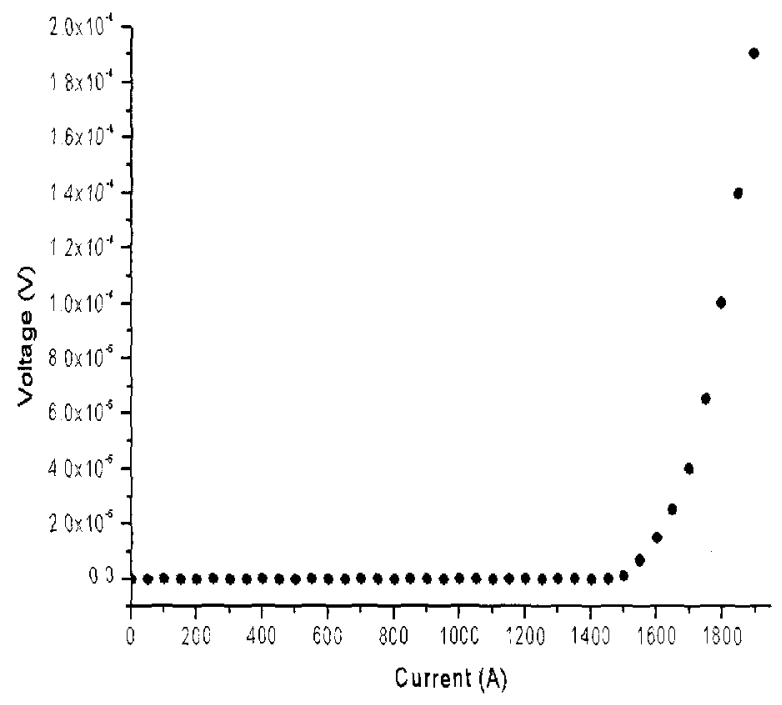

Fig. 8, I-V characteristics of $\mathrm{Bi} 2212$ tubes with 7 weight \% of $\mathrm{SrSO}_{4}$ additions at $35 \mathrm{~K}$. 


\section{CONCLUSION}

The tubes with 4 different chemical compositions were fabricated by CFP. Also the tube characteristics were systematically evaluated in terms of various $\mathrm{SrSO}_{4}$ amount in Bi2212. For tube fabrication the optimum range of melt temperatures and preheating temperature and time for mould were $1050{ }^{\circ} \mathrm{C}, 1100{ }^{\circ} \mathrm{C}$ and $550{ }^{\circ} \mathrm{C}$ for $30 \mathrm{~min}$ respectively. The applied mould rotating speed was $1000 \mathrm{rpm}$. Normally the specimen was mechanically stable when the melting temperature was over $1035{ }^{\circ} \mathrm{C}$ and steel mould was preheated over $400{ }^{\circ} \mathrm{C}$ for $30 \mathrm{~min}$. A tube was annealed at $840{ }^{\circ} \mathrm{C}$ in oxygen atmosphere for 72 hours.

XRD data suggest that the phase formed after direct solidification from melt was identified as amorphous phase and this phase was transformed into $\mathrm{Bi}$ based structure after heat treatment at $840{ }^{\circ} \mathrm{C}$ for 72 hours in oxygen atmosphere. The highly oriented plate-like grains were well developed along the rotating direction of mould regardless of initial chemical composition. Typical grain size was more than $20 \mu \mathrm{m}$. The specimen with 2212 composition exhibited $\mathrm{T}_{\mathrm{c}}$ of $83 \mathrm{~K}$ while the specimens with other composition are as low as $60 \mathrm{~K}$ or much lower than $60 \mathrm{~K}$ with a broad transition width and long tail, which is lower than what we expected. The measured $\mathrm{I}_{\mathrm{c}}$ and $\mathrm{J}_{\mathrm{c}}$ at $77 \mathrm{~K}(\mathrm{~B}=0 \mathrm{~T})$ in $\mathrm{Bi} 2212$ with 7 weight $\%$ of $\mathrm{SrSO}_{4}$ composition were about $680 \mathrm{~A}$ and $380 \mathrm{~A} / \mathrm{cm}^{2}$ and showed the highest as compared with other compositions.

\section{ACKNOWLEDGMENTS}

This research was supported by a grant from Center for Applied Superconductivity Technology of the 21st Century Frontier R\&D Program funded by the Ministry of Science and Technology, Republic of Korea.

\section{REFERENCES}

[1] H. Kumakura, K. Togano, J. Kase, T. Morimoto, and H. Maeda "Superconducting properties of textured $\mathrm{Bi}-\mathrm{Sr}-\mathrm{Ca}-\mathrm{Cu}$ tapes prepared by applying doctor blade casting", Cryogenics, Vol. 30, No. 11, p. 919 , 1990.

[2] H. Kitaguchi, H. Kumakura, and K. Togano, "Strain effect in $\mathrm{MgB}_{2}$ /stainless steel superconducting tape", Physica C: Supercond, Vol. 363, No. 3, p. 198, 2001.

[3] M. Schieber, "Deposition of high temperature superconducting films by physical and chemical methods", J. of Crystal Growth, Vol. 109, No. 1-4, p. $392,1991$.

[4] A. P. Malozemoff, Q. Li and S. Fleshler, "Progress in BSCCO-2223 tape technology", Physica C : Superconductivity, Vol. 2, No. 1, p. 424, 1997.

[5] Bock J, Bestgen H, Elschner S., and Preisler E, "Large shaped parts of melt cast BSCCO for applications in electrical engineering", IEEE Trans. Appl. Supercond, Vol. 3, No. 1, p. 16, 1993.

[6] P. F. Hermann, E. Beghin, and J. Bouthegourd, "Current transfer condition from a metallic conductor to a high $T_{c}$ superconductor", Cryogenices, Vol. 33, No. 1, p. $296,1993$.

[7] M. Chen, T. Baumann, P. Unternahere, and W. Paul, "Test of a 1.2 MVA high- $\mathrm{T}_{\mathrm{c}}$ superconducting fault current limiter", Physica C, Vol. 282, No. 1, p. 26, 1997.

[8] Hobl A, Krischel D., Schillo M, Schater P., Bock J., and Gauss S., "Qualification of MCP BSCCO-2121 bulk material for use in resistive current limiter", IEEE Trans. Appl. Supercond, Vol. 9, No. 2, p. 495, 1999.

[9] C. G. Kim and H. J. Jung, "Study on the formation mechanism of superconducting phases during annealing of sputtered $\mathrm{Bi}-\mathrm{Sr}-\mathrm{Ca}-\mathrm{Cu}-\mathrm{O}$ thin films", Physica C, Vol. 203, No. 1, p. 508, 1992.

[10] G. F. Voronin, "Thermodynamic characterization of high-temperature superconductors in the YBCO system", Pure Appl. Chem, Vol. 72, No. 3, p. 463, 2000. 